\title{
Observed and simulated swimming trajectories of late-stage coral reef fish larvae off the Florida Keys
}

\author{
Klaus B. Huebert*, Su Sponaugle \\ Division of Marine Biology and Fisheries, The Rosenstiel School of Marine and Atmospheric Science, University of Miami, \\ 4600 Rickenbacker Causeway, Miami, Florida 33149-1098, USA
}

\begin{abstract}
The supply of coral reef fish larvae from the open ocean to nearshore reefs is vital for the persistence of local fish populations. Larvae that are competent to settle are often fast swimmers, and their transport to suitable settlement habitat may depend on swimming behavior as well as currents. Our goal was to measure the effects of swimming behavior during the final period of larval transport. We observed late-stage bicolor damselfish Stegastes partitus larvae $1 \mathrm{~km}$ offshore of French Reef, Key Largo, Florida, USA, and recorded their in situ swimming trajectories. While all larvae swam remarkably straight, their swimming directions were distributed randomly. Larvae swam at speeds of 2 to $32 \mathrm{~cm} \mathrm{~s}^{-1}$ and transport due to swimming was of similar magnitude as transport due to cross-shore current, but much less than transport due to alongshore current. We used a simulation model to generate swimming trajectories of much longer duration than would be feasible to directly observe. This enabled us to better quantify the contribution of swimming behavior to larval transport. The observed and simulated swimming trajectories indicate that horizontal swimming by larvae with or without an external reference frame is important at spatial scales of several kilometers.
\end{abstract}

KEY WORDS: Fish larvae · Larval transport · Swimming behavior · Orientation · Coral reef

\section{INTRODUCTION}

At the beginning of their complex life cycle, coral reef fishes typically spend weeks to months developing in the open ocean as larvae. During this time, some larvae are transported large distances by ocean currents, while others are retained near their natal reefs (reviewed in Cowen \& Sponaugle 2009). Towards the end of the pelagic larval period, larvae become competent to metamorphose into juveniles and enter the final period of larval transport: some encounter suitable coral, seagrass, or mangrove habitat for settlement, leave the plankton, and become juveniles. Others fail to encounter suitable juvenile habitat, are unable to settle, and apparently perish. Given the urgent need to settle, active larval swimming towards settlement habitat may greatly enhance survival.

Several studies have provided circumstantial evidence for the potential importance of swimming behavior for larval transport. The swimming abilities of late-stage reef fish larvae are impressive: in laboratory experiments, average-performing larvae from average- performing families can achieve swimming speeds of $37 \mathrm{~cm} \mathrm{~s}^{-1}$ (Stobutzki \& Bellwood 1994, Fisher et al. 2005) and cover distances of $30 \mathrm{~km}$ without rest or food (Stobutzki \& Bellwood 1997). The mean speed of larvae in their natural environment is $20 \mathrm{~cm} \mathrm{~s}^{-1}$, as measured by SCUBA divers during the day (Leis \& Carson-Ewart 1997). At night, when most settlement occurs, swimming speeds may be higher, as is the case with some species reared and observed in aquaria (Fisher \& Bellwood 2003). Based on these findings, late-stage larvae appear to be capable of swimming 10s of kilometers per day. Additionally, larval swimming trajectories were found to be significantly straight (non-random), at least over the course of 10 min observations (Leis et al. 1996, Leis \& Carson-Ewart 2003). This is important, because frequent changes in direction could greatly reduce the cumulative effect of swimming behavior on transport. Further, late-stage larvae are attracted to odors (Sweatman 1988, Gerlach et al. 2007) and sounds (Tolimieri et al. 2004, Simpson et al. 2005) associated with coral reefs. Late-stage larvae within sensory range of a reef should consequently swim towards it. 
In situ observation of larvae by SCUBA divers is a proven method for studying larval fish behavior (reviewed in Leis 2006). Larvae generally do not appear stressed by the presence of the divers, engage in feeding behavior, and choose swimming directions independent of their orientation relative to the divers. Larvae have also been observed while schooling; besides slightly increased swimming speed and orienting ability, schools exhibit fundamentally similar behavior to individuals (Leis et al. 2009). To date, in situ observations of larvae by SCUBA divers have been conducted at various locations in the western and central Pacific, but predominantly at Lizard Island, Great Barrier Reef (GBR), Australia. Surprisingly, most larvae observed at Lizard Island actively avoid swimming towards the reef (Leis et al. 1996, Leis \& Carson-Ewart 2003). This may be because observations can only be conducted during the day, while most settlement takes place during the night. It also may be a reflection of the specific environment around Lizard Island, highlighting the need for similar studies across a greater range of different environments.

Here, we present the first data from in situ observations of fish larvae in the western Atlantic. We used a method similar to that of Leis \& Carson-Ewart (1997) to observe late-stage Stegastes partitus (bicolor damselfish) at French Reef, Key Largo, Florida, USA. Our objectives were to measure the degree to which larval swimming contributes to larval transport and to test whether reef fish larvae in an environment quite unlike Lizard Island behave similarly. Three key differences between Lizard Island and French Reef make the comparison noteworthy. First, French Reef has much lower biodiversity and biomass of animals than Lizard Island, typical for comparisons between the Florida Keys and the GBR. These differences may result in weaker cues for orientation. Second, French Reef is subject to much greater anthropogenic effects than Lizard Island. Landbased chemical pollution and boat noise may potentially disrupt natural olfactory and acoustic cues. Third, French Reef is part of the Florida Keys barrier reef system adjacent to the continental shelf break, while Lizard Island is sheltered inside the GBR lagoon. As a result, French Reef is exposed to much stronger currents, and the nearest coral reef in any offshore direction (NE through SW) is $>100 \mathrm{~km}$ distant, while Lizard Island is surrounded by mid-shelf reefs only $5 \mathrm{~km}$ away.

In addition to gathering field observations, we employed a simulation model to better quantify the importance of swimming behavior for larval transport in Stegastes partitus. Our model simulates larval swimming trajectories of much longer duration than would be feasible to observe directly. Simulated trajectories were then used to predict the upper and lower limits of the distance that late-stage larvae swim in situ, under the assumption that larval behavior over long and short periods of time is similar. Previous models have shown that, in a theoretical framework, the outcome of larval swimming towards coral reefs depends primarily on the parameters swimming speed, current speed, sensing ability, and orienting ability (Armsworth 2000, 2001, Codling et al. 2004). Our approach is novel in that we rely on bootstrapped empirical data, instead of exploring the theoretical parameter space.

\section{MATERIALS AND METHODS}

Collection. From May to September 2007, light-traps were deployed overnight near French Reef, Key Largo, Florida, USA. Late-stage larvae of various coral reef fish species are attracted to light-traps, and Stegastes partitus is the most commonly caught species in the upper Florida Keys (D'Alessandro et al. 2007). Sampling was focused on first-quarter and third-quarter moon phases, which is when late-stage $S$. partitus larvae are particularly abundant nearshore (D'Alessandro et al. 2007). Upon retrieving light-traps shortly after dawn, we placed larvae in a shaded bucket of seawater outfitted with a battery-operated aerator pump. Larvae were held for 2 to $11 \mathrm{~h}$ between retrieval and release, and water changes were performed regularly to ensure high water quality and to prevent overheating. During September, catches in Key Largo were supplemented with larvae caught using the same methods at American Shoals, Big Pine Key, and immediately couriered from Big Pine Key to Key Largo by car.

Field observations. Our methods for in situ observations of fish larvae by SCUBA divers were carried out according to Leis \& Carson-Ewart (1997). Slight modifications were made to meet safety recommendations of the American Association of Underwater Scientists for blue water diving (Heine 1986) and to address safety concerns regarding strong currents and heavy recreational boat traffic in the study area. All observations involved a designated data diver, a designated safety diver, and a boat operator. The data diver maintained constant visual contact with the larva and operated the data recorder, which consisted of a General Oceanics low-speed 2030 flowmeter, a compass, and a digital camera for recording flowmeter and compass readings (hereafter termed 'flompass'). The safety diver monitored dive time, depth, ascent rate, and environmental hazards, and towed a safety-line with a dive flag at the surface and a $2 \mathrm{~kg}$ weight at $18 \mathrm{~m}$. All observations were conducted near French Reef, between the 28 and $37 \mathrm{~m}$ isobaths, about $1 \mathrm{~km}$ offshore of the reef line.

The divers entered the water while the boat operator transferred 1 larva to a small plastic jar. The divers 
took the jar and descended to $5 \mathrm{~m}$ depth, where they oriented to face each other at a distance of $2 \mathrm{~m}$. The release direction, which was defined as the initial direction the data diver was facing, was randomized between N, E, W, and S. Meanwhile, the boat operator recorded the starting time, GPS (global positioning system) coordinates, and bottom depth sounding, and began circling the dive flag at a distance of about $50 \mathrm{~m}$ and a frequency of 1 full turn every few minutes. This was intended to evenly distribute any effect of boat noise on larval behavior across all directions (Leis \& Carson-Ewart 1997). The safety diver released the larva between the 2 divers and started a stopwatch timer. As the larva began swimming, the data diver followed $\sim 2 \mathrm{~m}$ behind and the safety diver moved into position beside the data diver, establishing touch contact. The safety diver prompted the data diver to record a flompass image every $30 \mathrm{~s}$ for a period of $10 \mathrm{~min}$. Simultaneous depth measurements were recorded with a Suunto D-3 dive computer. After completing each experiment, the divers attempted to recapture the larva with a hand-net and ascended to the surface. The boat operator quickly approached the divers and recorded the ending time, GPS coordinates, and bottom depth. These methods resulted in $\sim 30$ s measurements of heading and flow (from the flompass image) and depth (from the dive computer), as well as a single estimate for the net movement of the divers, including swimming as well as drift due to currents (from GPS coordinates).

Data analysis. Three-dimensional swimming and transport trajectories were reconstructed as follows. Horizontal swimming speeds were calculated from flow and elapsed time between consecutive flompass images. This method was calibrated by repeatedly timing the divers with a stopwatch as they swam a known distance at various speeds. During calibration, 95\% of flompass-derived speeds were accurate within $12 \%$ of the stopwatch-derived measurements. Headings were rounded to the nearest $10^{\circ}$ and used as estimates for swimming direction. Speed and direction time-series were converted from polar coordinates to Cartesian coordinates and combined with the depth time-series into 3-dimensional swimming trajectories. Lastly, average current was calculated from the change in the divers' GPS position over the course of the dive minus the change in position due to swimming. Net transport trajectories were constructed by sequentially adding drift (average current $\times$ elapsed time) to each interval of the swimming trajectories. For descriptive purposes, currents were divided into along-shore and crossshore components using the $50^{\circ}$ orientation of the $30 \mathrm{~m}$ isobath as the definition of along-shore.

Trajectories were analyzed with circular statistics, implemented in S-Plus by Insightful Corporation using the circstats library 2.0 by Lund (2004), following Jammalamadaka \& SenGupta (2001). Circular correlation (a circular analog of Pearson's correlation coefficient) between the initial release direction and larval swimming direction was used to determine whether the process of releasing larvae affected their behavior. For 3 min after release, there was a significant trend for larvae to swim in their randomized release directions $(p<0.05)$. These data points were considered biased and were excluded from all further analyses. Rayleigh's test was used to determine whether individual larvae swam randomly and whether the mean swimming directions of groups of different larvae were distributed randomly.

Simulation model. Field measurements of larval behavior were used to simulate swimming trajectories greatly exceeding the 10 min duration of observation experiments. Simulated larvae started at position $x=0$ and $y=0$ and alternated 'swimming' for 30 s and 'turning' to a new heading in an iterative process. Positive and negative movements along the $y$-axis were considered towards and away from coral reef settlement habitat, respectively. Movement along the $x$-axis was considered parallel to the barrier reef line. Ambient currents were not included explicitly in the model.

For each simulated trajectory, values of swimming speed and heading were generated by bootstrapping data from 1 randomly selected observation experiment. To address a range of larval sensory environments with respect to environmental cues for orientation to the reef, 3 different scenarios were examined: (1) larvae could orient directly towards the reef (each heading was drawn from the distribution of observed values rotated such that the mean pointed towards the reef); (2) larvae could orient with respect to an external reference frame, but could not sense the direction towards the reef (each heading was drawn from the distribution of observed values rotated such that the mean pointed in a random direction); and (3) larvae had no external frame of reference and moved in correlated random walks (each heading was generated from the previous heading plus a turn of magnitude drawn from the distribution of observed values and random direction). In each scenario, 10000 trajectories were simulated.

\section{RESULTS}

\section{Field observations}

In total, 60 observations of late-stage Stegastes partitus larvae were collected. In 30 cases, we collected a complete 10 min record of swimming behavior, and, in an additional 12 cases, we collected at least 5 min of 
data before encountering a problem (Fig. 1, Table 1). All 42 observations suitable for analysis were made on $8 \mathrm{~d}$ between May and September 2007. On some days visibility was sufficient for the divers to see the bottom during an observation, occasionally even from the surface. Larvae were successfully recaptured in 33 cases, and their standard length measurements were nor-

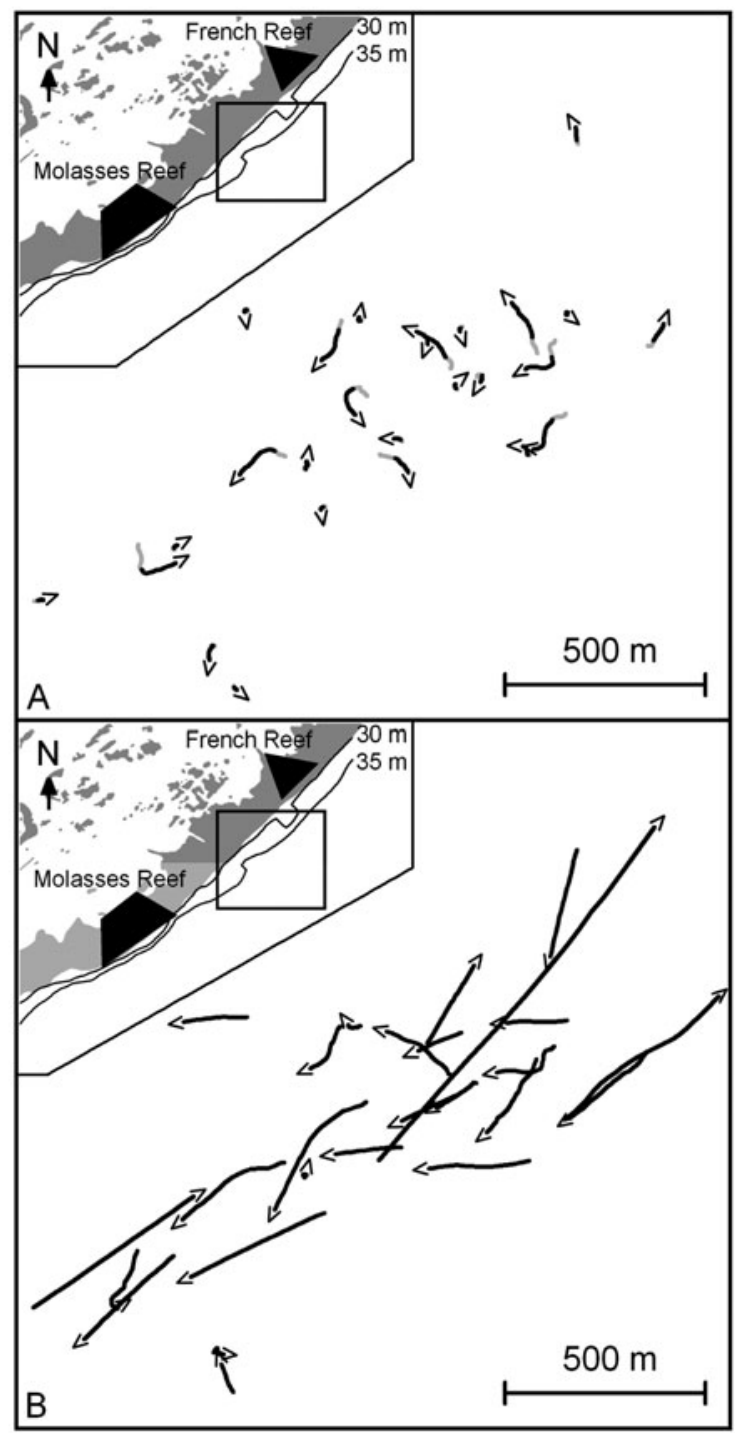

Fig. 1. Stegastes partitus. Trajectories of 26 late-stage larvae observed for $10 \mathrm{~min}$ by SCUBA divers. The inset shows the location of the plot area relative to the Florida Keys barrier reef. Gray areas: coral reefs; black polygons: sanctuary protected areas; lines: isobaths. (A) Larval swimming trajectories reconstructed from compass and flowmeter measurements. The first 3 min of trajectories (gray) were biased towards the release direction and were excluded from data analysis. Arrowheads point in the final direction of swimming measurements. (B) Larval transport due to swimming plus drift due to currents. Arrowheads point in the final direction of transport measurements. An additional 16 observations conducted outside of the plot area or for $<10 \mathrm{~min}$ are not shown
Table 1. Stegastes partitus. Summary of in situ observations of swimming behavior of late-stage larvae. Some were aborted to ensure the divers' safety when larvae exceeded $18 \mathrm{~m}$ depth, ascended faster than $18 \mathrm{~m} \mathrm{~min}^{-1}$, and, in one case, when a boat came dangerously close. Bold type indicates observations with sufficient data for analysis

\begin{tabular}{|lcc|}
\hline Duration (min) & Outcome & $\mathrm{n}$ \\
\hline 10 & Observation complete & $\mathbf{3 0}$ \\
$5-10$ & Larva lost & $\mathbf{5}$ \\
& Aborted - max. depth & $\mathbf{4}$ \\
& Aborted - ascent rate & $\mathbf{1}$ \\
& Aborted - boat traffic & $\mathbf{1}$ \\
$<5$ & Larva eaten & $\mathbf{1}$ \\
& Aborted - max. depth & 8 \\
& Larva lost & 7 \\
& Larva eaten & 2 \\
& Aborted - ascent rate & 1 \\
\hline
\end{tabular}

mally distributed with a mean $( \pm \mathrm{SD})$ of $10.5 \pm 0.7 \mathrm{~mm}$ (Shapiro-Wilks test, $\mathrm{p}=0.8$ ).

In all analyzed trajectories, larval swimming was directional, meaning significantly different from random (Rayleigh test, $\mathrm{p}<0.05$ ). Excluding the first $3 \mathrm{~min}$, during which larval swimming direction was significantly positively correlated with initial release direction, horizontal swimming trajectories were so straight that on average larvae covered $89 \%$ of the distance achievable by holding a perfectly straight line. The distribution of swimming directions appeared to be random (Fig. 2), lacking a significant sample mean direction (Rayleigh test, $\mathrm{p}=0.8$ ). Subsamples of trajectories grouped by various criteria (capture site, observation time and date, current speed and direction, tidal phase, lunar day, swimming speed and depth, standard length, bottom visibility) also lacked significant mean directions (Rayleigh test, $\mathrm{p}>0.05$ ).

The distribution of 3-dimensional mean swimming speed was bimodal, with 28 larvae swimming 2 to $13 \mathrm{~cm} \mathrm{~s}^{-1}$ and 14 larvae swimming 15 to $34 \mathrm{~cm} \mathrm{~s}^{-1}$ (Fig. 3). The horizontal component of swimming was $\sim 5 \mathrm{~cm} \mathrm{~s}^{-1}$ in the slow group and $\sim 24 \mathrm{~cm} \mathrm{~s}^{-1}$ in the fast group, resulting in horizontal swimming trajectories of 10 to $152 \mathrm{~m}$ length $($ mean $=56 \mathrm{~m}$ ). The vertical component of mean swimming speed was $\sim 3 \mathrm{~cm} \mathrm{~s}^{-1}$ in the slow group and $\sim 5 \mathrm{~cm} \mathrm{~s}^{-1}$ in the fast group, respectively. Currents were highly variable in speed and direction. The along-shore component, which ranged from $76 \mathrm{~cm} \mathrm{~s}^{-1} \mathrm{SW}$ to $162 \mathrm{~cm} \mathrm{~s}^{-1} \mathrm{NE}$, tended to dominate the cross-shore component, which ranged from $27 \mathrm{~cm} \mathrm{~s}^{-1} \mathrm{NW}$ to $27 \mathrm{~cm} \mathrm{~s}^{-1}$ SE. The mean absolute current (scalar) was $40 \mathrm{~cm} \mathrm{~s}^{-1}$ and the mean current velocity vector was $3 \mathrm{~cm} \mathrm{~s}^{-1} \mathrm{~N}$. No vertical component of current was apparent. The average depth of swimming trajectories appeared to be normally distributed with a mean of $9.9 \mathrm{~m}(\mathrm{SD}=2.5 \mathrm{~m})$ (Shapiro-Wilks test, $\mathrm{p}=0.7$ ), 


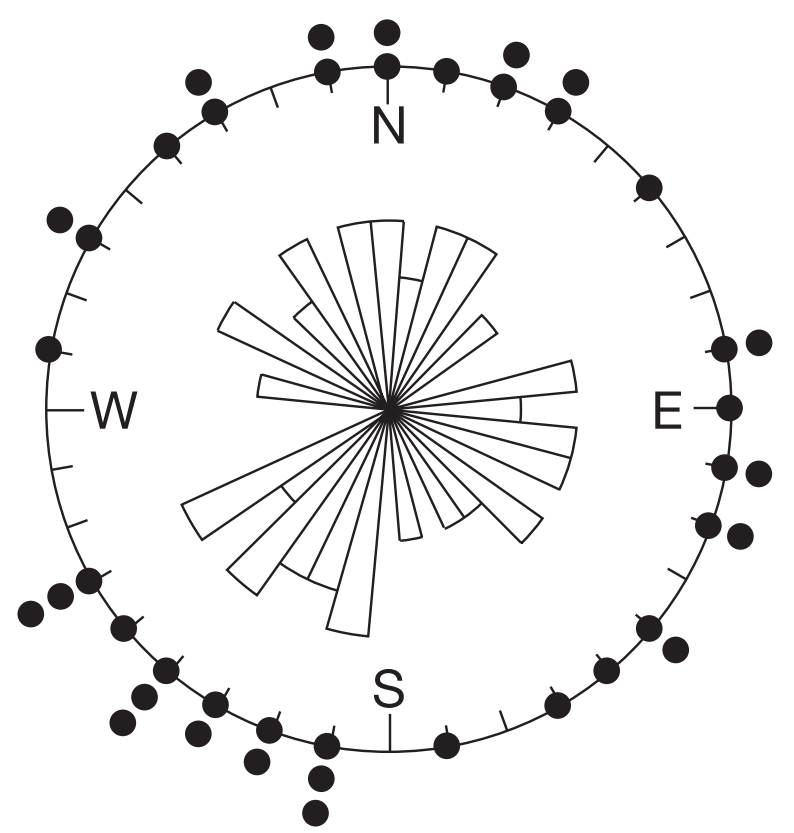

Fig. 2. Stegastes partitus. Each point on the compass represents the mean swimming direction of 1 late-stage larva observed for 5 to $10 \mathrm{~min}$ off the Florida Keys. The area of each rose petal at the center of the diagram represents the frequency of mean directions. Individual mean directions were all statistically significant (Rayleigh test, $\mathrm{p}<0.05$ ), but the distribution of mean directions was random (Rayleigh test, $\mathrm{p}=0.8$ )

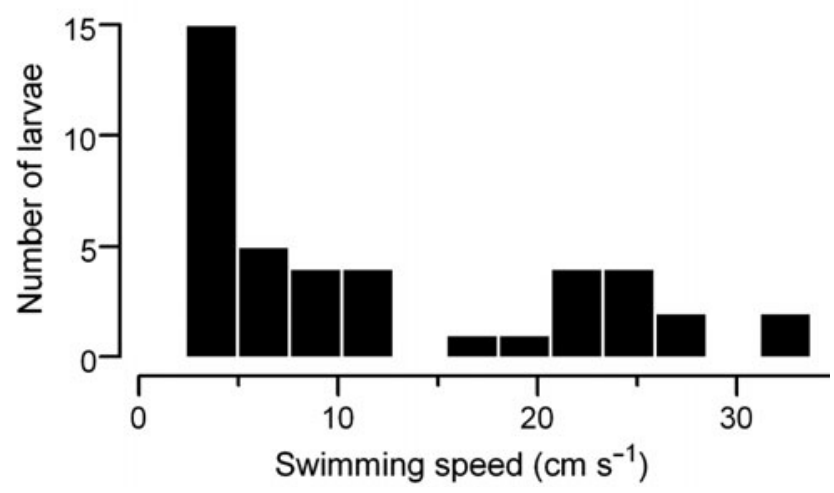

Fig. 3. Stegastes partitus. Mean in situ swimming speeds of late-stage larvae observed by SCUBA divers off the Florida Keys

but may have been biased by 4 trajectories that exceeded the maximum depth of the divers (Fig. 4). The median depth of $9.7 \mathrm{~m}$ and the inter-quartile range of $3.9 \mathrm{~m}$ are more robust statistics.

\section{Simulation model}

As expected, model output varied greatly between the 3 scenarios (Fig. 5). In Scenario 1, larvae moved steadily towards the reef making progress at a mean

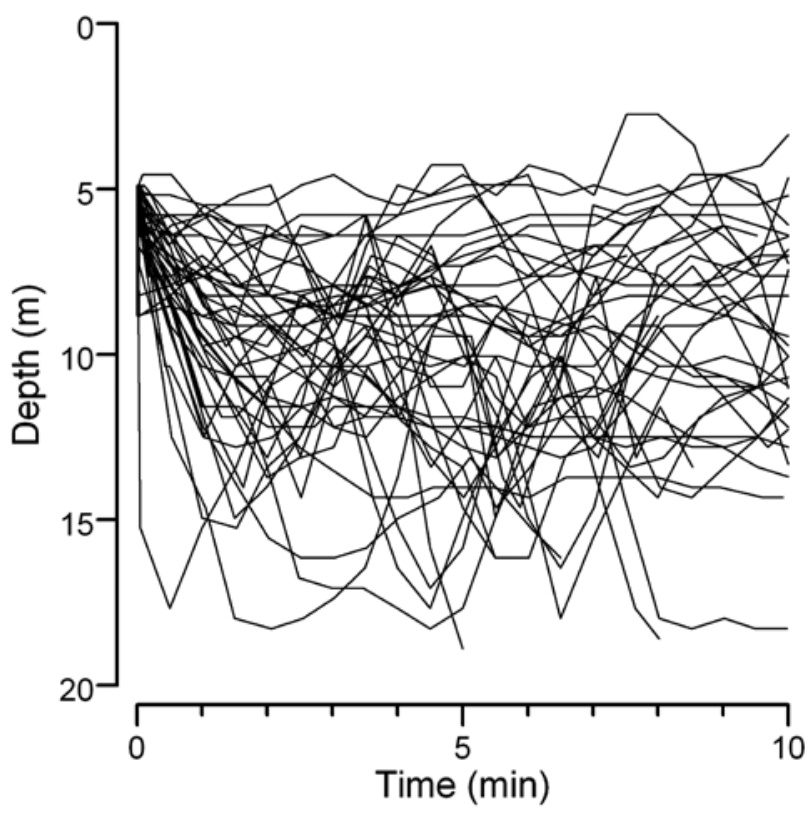

Fig. 4. Stegastes partitus. Swimming depths of all 42 latestage larvae observed for $>5$ min off the Florida Keys. Larvae were individually released at $5 \mathrm{~m}$, and mostly swam within a narrow range of 5 to $15 \mathrm{~m}$ depth

$( \pm \mathrm{SD})$ of $10 \pm 9 \mathrm{~cm} \mathrm{~s}^{-1}$. In Scenario 2, larvae moved steadily away from the release point, traveling equivalent distances as in Scenario 1, but spread out evenly over all directions. In Scenario 3, larvae spread out in all directions and initially made similar progress as in Scenario 2, but this diminished over time as their correlated random walks resulted in meandering trajectories. For simple comparisons among the scenarios, results can be expressed as the proportion of larvae encountering the reef as a function of distance and time (Table 2). In $1 \mathrm{wk}$ the top $10 \%$ of simulated larvae in each of the scenarios swam $>130,>70$, and $>3 \mathrm{~km}$ towards the reef, respectively.

\section{DISCUSSION}

Swimming and orienting behaviors by pelagic larvae of benthic fishes potentially affect both the supply of larvae to populations on a local scale, as well as the ecological connectivity among populations on a regional scale. During in situ observations of the behavior of late-stage Stegastes partitus larvae, we made direct measurements of larval swimming directionality, swimming speed, and vertical distribution in the western Atlantic. We modeled our observation methods after those by Leis \& Carson-Ewart (1997); thus, direct comparisons can be made to several similar studies conducted in the western Pacific (mostly at 

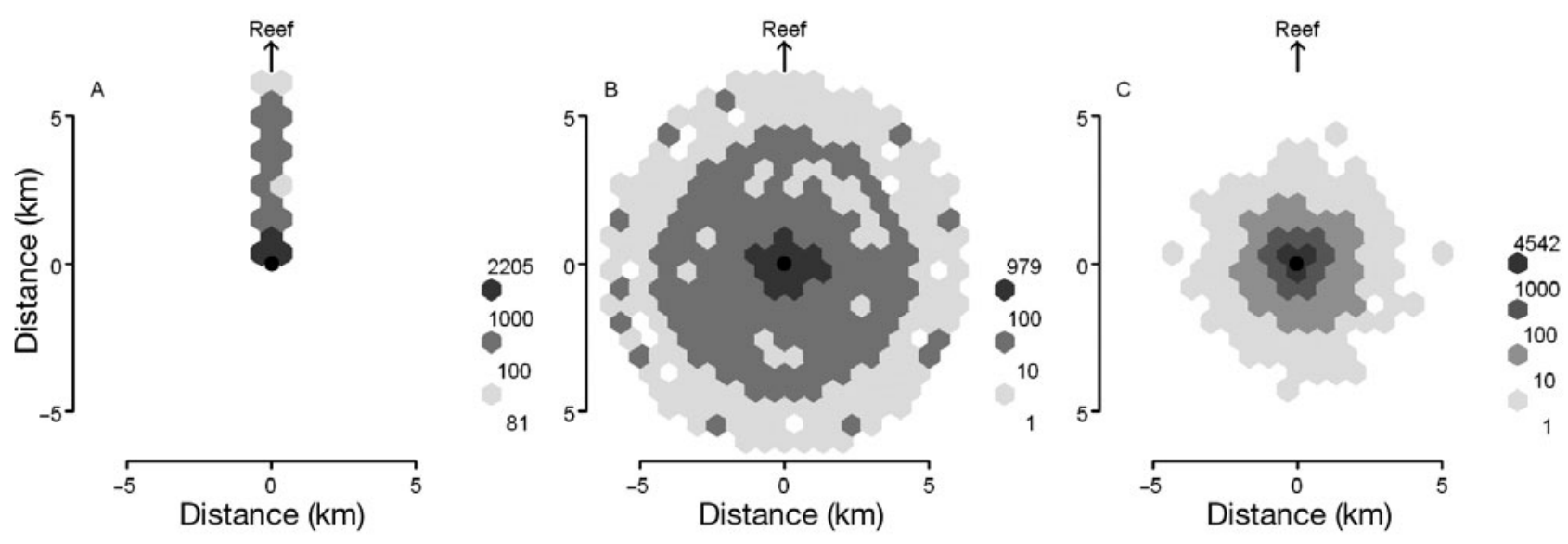

Fig. 5. Stegastes partitus. Distributions of 10000 simulated late-stage larvae 100 min after release at the center of the plot $(\bullet)$. Swimming speeds and directions for each larva were generated by resampling empirical data from 1 S. partitus observed in situ. Darker shading indicates higher numbers of larvae. (A) Scenario 1: larvae sense a reef and persistently swim towards it. (B) Scenario 2: larvae orient using a reef-independent reference frame and persistently swim in a random direction. Some swim large distances towards the reef without being able to sense it. (C) Scenario 3: larvae with no frame of reference spread out more slowly. Nevertheless, some cover substantial distances towards the reef

Table 2. Comparisons between larval dispersal due to simulated swimming behavior in 3 model scenarios at 3 orders of magnitude in temporal and spatial scales. Values represent the fraction (\%) of larvae swimming a particular distance towards the reef within a particular time

\begin{tabular}{|lrrrr|}
\hline \multirow{2}{*}{ Scenario } & Spatial & \multicolumn{3}{c|}{ Temporal scale } \\
\cline { 3 - 5 } & Scale & $100 \mathrm{~min}$ & $\begin{array}{c}1000 \mathrm{~min} \\
(\sim 17 \mathrm{~h})\end{array}$ & $\begin{array}{c}10000 \mathrm{~min} \\
(\sim 1 \mathrm{wk})\end{array}$ \\
\hline (1) Larvae persistently & $1 \mathrm{~km}$ & 29 & 100 & 100 \\
swim towards reef & $10 \mathrm{~km}$ & 0 & 29 & 100 \\
& $100 \mathrm{~km}$ & 0 & 0 & 29 \\
(2) Larvae persistently & $1 \mathrm{~km}$ & 6 & 37 & 49 \\
swim in a random direction & $10 \mathrm{~km}$ & 0 & 6 & 37 \\
& $100 \mathrm{~km}$ & 0 & 0 & 6 \\
(3) Larvae swim in & $1 \mathrm{~km}$ & 1 & 17 & 46 \\
correlated random walks & $10 \mathrm{~km}$ & 0 & 0 & 2 \\
& $100 \mathrm{~km}$ & 0 & 0 & 0 \\
\hline
\end{tabular}

Lizard Island, GBR) and central Pacific. Our use of in situ data in modeling larval behavior is novel, and provides a simple framework for extrapolating from brief field observations to temporal scales of days or weeks.

\section{Directionality}

The majority of late-stage coral reef fish larvae observed in open water during previous studies in the Pacific swam directionally, i.e. they made significant progress in a particular direction (reviewed in Leis 2006). Given sufficient sample sizes, larvae frequently swam in significantly similar directions, i.e. the distribution of individual directions was non-random, either in terms of compass heading or, more commonly, relative to the reef (reviewed in Leis 2006). The latter provided evidence that some larvae actively navigate, using cues associated with the reef.

In our study, each Stegastes partitus trajectory was individually directional, but, at the sample level, the 42 trajectories were evenly distributed over all possible directions. Swimming in apparently random directions suggests that larvae may have lacked environmental cues for navigation. On the GBR, some larvae may be able to detect biological noise produced by healthy reef communities over distances of 'many' kilometers (Wright et al. 2005), and olfactory sensitivity to persistent odor plumes may facilitate homing over $20 \mathrm{~km}$ (Gerlach et al. 2007). However, reefs in the Florida Keys are of comparatively lower biodiversity and biomass, presumably resulting in weaker 'beacons' for larvae to follow. Further, Key Largo is subject to substantial anthropogenic impacts, and natural stimuli such as reef odor and sound may be obscured by pollution and boat noise. Finally, odor plumes are unlikely to persist in the study area, due to strong and variable currents. If larvae lacked an external reference frame for orientation, then the straightness of individual trajectories is remarkable and calls for an alternative explanation. Codling et al. (2004) suggested thinking of larval swimming as a correlated random walk process, where any given heading depends only on the previous head- 
ing modified by a turn. Given small turns, a correlated random walk can be very straight for short periods of time with or without orienting behavior. Additionally, fishes may limit the rate at which their swimming direction changes, based on endogenous inertial cues detected by the vestibular system (Harden Jones 1984, Levin \& Gonzalez 1994). The implications of larvae following correlated random walk trajectories are further explored in our simulation model.

The fact that Stegastes partitus larvae swam in different directions does not rule out the possibility that larvae were able to sense the reef. The benefits of moving to or from the reef under experimental conditions are unclear. At Lizard Island, the most common pattern of behavior is for larvae to swim away from the reef during the day (Leis et al. 1996), presumably to avoid visual predators and delay settlement until nightfall. Our data do not suggest that diurnal swimming directions of $S$. partitus larvae were related to settlement. Nighttime SCUBA observations have not been attempted, but orientation towards reef cues during the night has been demonstrated on smaller spatial scales using other methods (Tolimieri et al. 2004, Simpson et al. 2005).

\section{Larval transport}

Simultaneous measurements of swimming speed and Lagrangian current (i.e. drift) provide direct insight into the influence of behavior on larval transport in a dynamic oceanographic system. Mean horizontal in situ swimming speeds of 2 to $32 \mathrm{~cm} \mathrm{~s}^{-1}$ for Stegastes partitus in our study are comparable to 2 to $40 \mathrm{~cm} \mathrm{~s}^{-1}$ among damselfishes and 1 to $65 \mathrm{~cm} \mathrm{~s}^{-1}$ among other late-stage coral reef fish larvae observed in Australia and Polynesia (Leis \& Carson-Ewart 1997). The critical swimming speed of late-stage $S$. partitus, which leads to exhaustion within a few minutes, is $\sim 43 \mathrm{~cm} \mathrm{~s}^{-1}$, as determined in laboratory experiments in the Turks and Caicos Islands (Fisher et al. 2005). It is typical for in situ speeds to be approximately half of critical swimming speeds (reviewed in Leis 2006). Thus, the expected in situ speed for $S$. partitus should be $\sim 22 \mathrm{~cm} \mathrm{~s}^{-1}$, which falls within the 2 to $32 \mathrm{~cm} \mathrm{~s}^{-1}$ range of our observed measurements, but is higher than the observed mean of $11 \mathrm{~cm} \mathrm{~s}^{-1}$.

For a location so close to the reef, the currents we measured were extremely variable and strong. We expected NE currents with a mean $( \pm$ SD) speed of $20 \pm$ $18 \mathrm{~cm} \mathrm{~s}^{-1}$, based on long-term measurements at 7 and $17 \mathrm{~m}$ depths near the $30 \mathrm{~m}$ isobath at nearby Carysford Reef (Lee \& Williams 1999) and consistent with measurements at $4 \mathrm{~m}$ depth near the $24 \mathrm{~m}$ isobath at French Reef (Sponaugle et al. 2005). We observed over 3 times the anticipated range of current speeds (80 $\mathrm{cm} \mathrm{s}^{-1} \mathrm{SE}$ to $162 \mathrm{~cm} \mathrm{~s}^{-1} \mathrm{NW}$ ). Differences between Lagrangian current measurements (drift of a particular parcel of water) and Eulerian current measurements (flow past a particular location) may have contributed to the discrepancy, but, more importantly, our measurements reflected average currents over $\sim 10 \mathrm{~min}$ duration and captured short-term variability that was removed by Lee \& Williams (1999) and Sponaugle et al. (2005) through $40 \mathrm{~h}$ low-pass filtering. Our measurements are well within the documented mean speeds of the nearby Florida Current (e.g. Leaman et al. 1987).

For comparisons between swimming and current speed measurements, larvae are often categorized as either effective or ineffective swimmers, depending on their ability to swim faster than the average current. Applying the idea of effective swimming to our data is complex, because the concept of 'average' current is ambiguous and potentially misleading. The mean current speed scalar of $40 \mathrm{~cm} \mathrm{~s}^{-1}$ was faster than the fastest larvae, while the mean current velocity vector of $3 \mathrm{~cm} \mathrm{~s}^{-1}$ (to the north) was roughly equivalent to the slowest larvae. Further, variability in magnitude and direction of current was so great that most larvae experienced currents that were quite different from the mean. Finally, in the context of swimming to settlement habitat, the cross-shore component is much more important than the along-shore component of current. Since the barrier reef tract is essentially linear in nature and extends for $\sim 350 \mathrm{~km}$, movement along the reef may be inconsequential for settlement (on a short time scale), while cross-shore movement is critical. To take the variability in current magnitude and direction into account, we calculated the ratio of transport by swimming and transport by cross-shore current. This metric expresses the degree to which larval swimming was 'effective' quantitatively and explicitly incorporates the imperfect ability of larvae to orient. We found that larval swimming accounted for a mean $( \pm \mathrm{SD})$ of $48 \pm 29 \%$ of cross-shore drift plus distance swum. In other words, larval behavior and cross-shore currents contributed equal parts to net transport on the time scale of in situ observations.

\section{Vertical distribution}

Vertical swimming of Stegastes partitus larvae is of particular interest, because currents and potential cues for orientation can vary with depth. It was clear from direct observations that larvae swam to particular depths, as opposed to arriving there by currents or buoyancy. Over individual $30 \mathrm{~s}$ time steps, swimming speeds in excess of $20 \mathrm{~cm} \mathrm{~s}^{-1}$ down and $17 \mathrm{~cm} \mathrm{~s}^{-1}$ up 
(limited by the divers' ability to safely follow) were observed. Overall, $23 \%$ of swimming activity was along the vertical axis. In oceanic water off of Barbados, $S$. partitus larvae migrate with ontogeny from a region of offshore flow at 0 to $20 \mathrm{~m}$ depth during their pre-flexion stage to a region of onshore flow deeper than $20 \mathrm{~m}$ during their post-flexion stage (Paris \& Cowen 2004). If larvae behave similarly in the Florida Straits, then the narrow distribution we observed (mean $\pm \mathrm{SD}, 9.9 \pm 2.5 \mathrm{~m}$ ) may represent a second vertical migration from $>20 \mathrm{~m}$ depth to $\sim 10 \mathrm{~m}$ at the very end of the pelagic larval phase. Vertical distributions of 13 late-stage damselfish species at Lizard Island were similarly shallow and narrow, with a mean $( \pm \mathrm{SD})$ depth of $7.7 \pm 2.8 \mathrm{~m}$ (Leis et al. 1996).

The mechanisms underlying depth regulation by pelagic fish larvae are not well understood. At Lizard Island, some larvae swim at shallower depths when more upwelling light is visible (over a reflective sandy bottom), possibly to maintain a minimum distance from the bottom (Leis 2004). In our study, the bottom was clearly visible from the surface on some days, but uniformly dark blue on others (true blue-water conditions). We saw no effect of visibility on larval behavior. Damselfish larvae may also use a sense of hydrostatic pressure to regulate their depth, as has been demonstrated in coral reef fish larvae from other families (Huebert 2008).

\section{Simulation model}

The purpose of our model was to evaluate the effects of swimming behavior on larval transport at the end of the pelagic larval stage. Three different scenarios simulated larvae: (1) swimming towards the reef, (2) swimming in a random direction, or (3) swimming with no directional preference (following correlated random walks). The scenarios are equivalent to navigation with compass and map, orientation by compass only, and non-oriented movement, respectively. In all cases, swimming trajectories were generated by resampling in situ data, under the assumption that larval behavior over long and short periods of time is similar. Since field observations were conducted exclusively $\sim 1 \mathrm{~km}$ from the reef line, the model may overestimate the straightness of trajectories at greater distances from the reef. However, we consider this unlikely because larvae did not appear to benefit from their close proximity to the reef in terms of orientation, as demonstrated by dissimilar swimming directions.

Larvae that were able to sense the reef, i.e. Scenario 1 , approached the reef quickly (mean \pm SD: $10 \pm$ $9 \mathrm{~cm} \mathrm{~s}^{-1}$ ). These results are similar in speed to estimates based on laboratory speed measurements by
Stobutzki \& Bellwood (1997) and similar in straightness to the correlated random walk model by Codling et al. (2004) at the upper limit of sensing and orienting ability considered. As discussed above, the range at which larvae might sense reefs in the Florida Keys is uncertain. However, Scenario 1 is unrealistic for the majority of pelagic coral reef fish larvae, which are found at high concentrations at distances up to $40 \mathrm{~km}$ or more offshore in the Straits of Florida (e.g. Llopiz \& Cowen 2009, Sponaugle et al. 2009).

An upper limit of larval transport via horizontal swimming without reef-based cues is given by Scenario 2 , in which larvae persistently swim in a random direction. A lower limit is given by Scenario 3, in which larvae swim in correlated random walks. Scenarios 2 and 3 both predict that some larvae swim substantial distances towards the reef despite lacking the ability to sense the reef. This is a major departure from the common assumption that swimming by disoriented larvae is irrelevant and negligible. To put the model results in perspective, consider a cohort of entirely passive larvae and a cohort of actively swimming larvae, each located several kilometers from suitable settlement habitat, but unable to sense their proximity across this distance. Lacking favorable ocean currents, the cohort of passive larvae has no chance of recruitment and perishes entirely. The cohort of active larvae, on the other hand, has a much greater recruitment potential than the passive cohort (Table 2). Additionally, larvae swimming towards the reef by chance will increase their odds of detecting reef-based cues, which may then facilitate proper navigation to the reef as in Scenario 1.

\section{Conceptual framework}

With respect to the influence of horizontal swimming on transport and settlement, the early life history of reef fishes can be divided into 3 successive phases. In Phase 1, horizontal swimming is of no importance. Phase 1 is not directly addressed in our study, but certainly includes non-motile eggs, almost certainly includes slow-swimming pre-flexion larvae (Fisher et al. 2000), probably includes post-flexion larvae until they become competent to settle, and is less likely to include late-stage larvae. In the previously undescribed Phase 2, larvae lacking the environmental cues for proper navigation nevertheless actively swim distances of up to several kilometers, which increases their chance of coming within sensory range of settlement habitat. The transition to Phase 2 may be limited by the development of swimming ability (Fisher et al. 2000), or it may take place around the time larvae become competent to settle. In the final phase (3), lar- 
vae become able to sense environmental cues useful for navigation and settlement, either due to increased larval development or increased quality of available environmental cues. Late-stage larvae that actively select settlement sites (Sweatman 1988, Danilowicz 1996) clearly fall into Phase 3, as do larvae that navigate away from the nearest reef (Leis et al. 1996, Leis \& Carson-Ewart 2003). In environments with strong cues for orientation (possibly including Lizard Island), Phase 3 may be of particular importance. In environments with weak cues (possibly including the upper Florida Keys), Phase 2 may be prolonged and Phase 3 quite short. In a few cases, transport may take place entirely during Phase 1, with larvae acting as passive particles until they arrive and settle in suitable habitat. Finally, movement away from settlement habitat or a deterioration of available cues, for example, softer reef sounds during the day than during the night (Cato 1978, McCauley \& Cato 2000), may result in larvae losing orientation and reverting from Phase 3 to 2 . Further study is needed to determine the temporal and spatial scales of each phase and to validate their general importance for larval transport.

\section{Summary}

A better understanding of small-scale physical circulation patterns and species-specific behaviors may greatly advance the study of larval transport and marine population connectivity (reviewed in Werner et al. 2007). In the case of late-stage Stegastes partitus larvae in the upper Florida Keys, observed and simulated swimming trajectories indicate that horizontal swimming by larvae with or without an external reference frame is important at spatial scales of several kilometers. S. partitus larvae swim at speeds typical for other coral reef fish larvae (Fisher et al. 2005) and encountered very strong currents during our study. Therefore, horizontal swimming by larvae of a diversity of reef fishes may account for the several kilometers of transport immediately preceding settlement.

Acknowledgements. Financial support for this study was provided by NSF Grant No. OCE-0550732 to S.S., R. Cowen, C. Paris, and V. Kourafalou, a Harding Michel Fellowship to K.H., and scholarships from the Miami Billfish Tournament to K.H. Methods were approved in University of Miami Animal Care and Use Committee Protocols 05-019 and 07-068. Many thanks to T. Rankin and K. Walter for diving, and to K. Shulzitski, C. Boynton, E. Buck, E. D'Alessandro, and C. Kelble for operating the boat. J. Leis trained K.H. in conducting in situ observations. The diving protocol was developed in collaboration with R. Gomez. J. Serafy provided boat time for a preliminary study. T. Murphy couriered larvae. A. Chapin helped develop the flompass instrument. Many of the above individuals and several interns and volunteers deployed light-traps and assisted at sea. The manuscript was greatly improved upon thanks to comments and discussions with R. Cowen, J. Hare, J. Serafy, M. Schmale, L. Zamora, and 3 anonymous reviewers.

\section{LITERATURE CITED}

Armsworth PR (2000) Modelling the swimming response of late stage larval reef fish to different stimuli. Mar Ecol Prog Ser 195:231-247

Armsworth PR (2001) Directed motion in the sea: efficient swimming by reef fish larvae. J Theor Biol 210:81-91

> Cato DH (1978) Marine biological choruses observed in tropical waters near Australia. J Acoust Soc Am 64:736-743

> Codling EA, Hill NA, Simpson SD (2004) Random walk models for the movement and recruitment of reef fish larvae. Mar Ecol Prog Ser 279:215-224

Cowen RK, Sponaugle S (2009) Larval dispersal and marine population connectivity. Annu Rev Mar Sci 1:443-466

> D'Alessandro E, Sponaugle S, Lee T (2007) Patterns and processes of larval fish supply to the coral reefs of the upper Florida Keys. Mar Ecol Prog Ser 331:85-100

Danilowicz BS (1996) Choice of coral species by naive and field-caught damselfish. Copeia 1996:735-739

Fisher R, Bellwood DR (2003) Undisturbed swimming behaviour and nocturnal activity of coral reef fish larvae. Mar Ecol Prog Ser 263:177-188

> Fisher R, Bellwood DR, Job SD (2000) Development of swimming abilities in reef fish larvae. Mar Ecol Prog Ser 202: 163-173

> Fisher R, Leis J, Clark D, Wilson S (2005) Critical swimming speeds of late-stage coral reef fish larvae: variation within species, among species and between locations. Mar Biol 147:1201-1212

Gerlach G, Atema J, Kingsford MJ, Black KP, Miller-Sims V (2007) Smelling home can prevent dispersal of reef fish larvae. Proc Natl Acad Sci USA 104:858-863

Harden Jones FR (1984) Could fish use inertial cues when on migration? NATO Conf Ser 4 14:67-78

Heine JN (1986) Blue water diving guidelines. California Sea Grant College Program, La Jolla, CA

> Huebert KB (2008) Barokinesis and depth regulation by pelagic coral reef fish larvae. Mar Ecol Prog Ser 367:261-269

Jammalamadaka SR, SenGupta A (2001) Topics in circular statistics. World Scientific, River Edge

> Leaman KD, Molinari RL, Vertes PS (1987) Structure and variability of the Florida Current at $27^{\circ} \mathrm{N}$ : April 1982-July 1984. J Phys Oceanogr 17:565-583

Lee TN, Williams E (1999) Mean distribution and seasonal variability of coastal currents and temperature in the Florida Keys with implications for larval recruitment. Bull Mar Sci 64:35-56

> Leis JM (2004) Vertical distribution behaviour and its spatial variation in late-stage larvae of coral-reef fishes during the day. Mar Freshwat Behav Physiol 37:65-88

> Leis JM (2006) Are larvae of demersal fishes plankton or nekton? Adv Mar Biol 51:57-141

> Leis JM, Carson-Ewart BM (1997) In situ swimming speeds of the late pelagic larvae of some Indo-Pacific coral-reef fishes. Mar Ecol Prog Ser 159:165-174

- Leis JM, Carson-Ewart BM (2003) Orientation of pelagic larvae of coral-reef fishes in the ocean. Mar Ecol Prog Ser 252:239-253

Leis JM, Sweatman HPA, Reader SE (1996) What the pelagic stages of coral reef fishes are doing out in blue water: daytime field observations of larval behavioural capabilities. 
Mar Freshw Res 47:401-411

Leis JM, Irisson JO, Paris CB, Yerman M (2009) With a little help from your friends: group navigation in larval reef fish. In: 33rd Larval Fish Conference. Portland, OR, Early Life History Section (ELHS) (Conference presentation abstract) (available at www.dce.k-state.edu/conf/jointmeeting/docs/ jmih_09\%20abstracts_F-L.pdf

Levin LE, Gonzalez O (1994) Endogenous rectilinear guidance in fish - Is it adjusted by reference to the sun? Behav Processes 31:247-255

> Llopiz JK, Cowen RK (2009) Variability in the trophic role of coral reef fish larvae in the oceanic plankton. Mar Ecol Prog Ser 381:259-272

Lund UJ (2004) CircStats: S-PLUS Functions for circular statistics. Available at: http://statweb.calpoly.edu/ulund/ (accessed on 19 June 2009)

McCauley RD, Cato DH (2000) Patterns of fish calling in a nearshore environment in the Great Barrier Reef. Philos Trans R Soc Lond B 355:1289-1293

Paris CB, Cowen RK (2004) Direct evidence of a biophysical retention mechanism for coral reef fish larvae. Limnol Oceanogr 49:1964-1979

Simpson SD, Meekan M, Montgomery J, McCauley R, Jeffs A (2005) Homeward sound. Science 308:221

Editorial responsibility: Matthias Seaman, Oldendorf/Luhe, Germany
Sponaugle S, Lee T, Kourafalou V, Pinkard D (2005) Florida Current frontal eddies and the settlement of coral reef fishes. Limnol Oceanogr 50:1033-1048

Sponaugle S, Llopiz JK, Havel LN, Rankin TL (2009) Spatial variation in larval growth and gut fullness in a coral reef fish. Mar Ecol Prog Ser 383:239-249

Stobutzki IC, Bellwood DR (1994) An analysis of the sustained swimming abilities of presettlement and postsettlement coral-reef fishes. J Exp Mar Biol Ecol 175:275-286

Stobutzki IC, Bellwood DR (1997) Sustained swimming abilities of the late pelagic stages of coral reef fishes. Mar Ecol Prog Ser 149:35-41

> Sweatman H (1988) Field evidence that settling coral-reef fish larvae detect resident fishes using dissolved chemical cues. J Exp Mar Biol Ecol 124:163-174

Tolimieri N, Haine O, Jeffs A, McCauley R, Montgomery J (2004) Directional orientation of pomacentrid larvae to ambient reef sound. Coral Reefs 23:184-191

Werner FE, Cowen RK, Paris CB (2007) Coupled biological and physical models. Oceanography (Wash DC) 20:54-69

Wright KJ, Higgs DM, Belanger AJ, Leis JM (2005) Auditory and olfactory abilities of pre-settlement larvae and postsettlement juveniles of a coral reef damselfish (Pisces: Pomacentridae). Mar Biol 147:1425-1434

Submitted: June 4, 2009; Accepted: October 12, 2009

Proofs received from author(s): October 29, 2009 